\title{
Mental health care for hospitalized COVID-19 patients; an experience from Iran
}

\author{
Fatemeh Sadat Mirfazeli ${ }^{1}$, Seyed Hamid Reza Faiz ${ }^{2}$, Behnam Shariati ${ }^{1}$, Poupak Rahimzadeh*2 $\mathbb{E}$, Saeed Kalantari ${ }^{3}$
}

Received: 12 Jul $2020 \quad$ Published: 2 Dec 2020

Conflicts of Interest: None declared

Funding: None

*This work has been published underCC BY-NC-SA 1.0 license.

Copyright $₫$ Iran Universitv of Medical Sciences

Cite this article as:Mirfazeli FS, Faiz SHR, Shariati B, Rahimzadeh P, Kalantari S. Mental health care for hospitalized COVID-19 patients; an experience from Iran.Med J Islam Repub Iran. 2020(2 Dec);34:162. https://doi.org/10.47176/mjiri.34.162

Up to May, 2020, the new coronavirus (COVID-19) has infected 6057853, with 371166 deaths worldwide (1). High contagiousness of the disease, shortage of medical facilities, lack of definitive treatment, and self-quarantine have all caused confusion, anxiety, and depression among COVID-19 patients. These patients are being admitted to hospitals without any companion and may face complex psychological issues (2). Moreover, psychiatric complications of COVID-19 have been reported in 59\% of patients in a recent study (3). Such obstacles and their psychological consequences may be overlooked due to the heavy workload of health care professionals and communication barriers due to use of protective equipment. Based on our experience in Rasoul Akram hospital, Iran, with at least 25 psychiatric consultations per month for COVID-19 patients, addressing the following items would be beneficial for the mental health care of hospitalized patients with COVID-19.

\section{Mental healthcare in a hospital ward}

\section{(1) Provide leisure activities in wards}

Physicians reveal how the patients usually spend their leisure time. We routinely asked these questions from the patient or the family after taking medical history. Based on the answers, we offered some feasible hobbies to pa-

Corresponding author: Dr Poupak Rahimzadeh, rahimzadeh.p@iums.ac.ir

1. Mental Health Research Center, Iran University of Medical Sciences, Tehran, Iran

2. Rasoul Akram Hospital Clinical Research Development Center (RCRDC), Iran University of Medical Sciences, Tehran, Iran

3. Antimicrobial Resistance Research Center, Iran University of Medical Sciences, Tehran, Iran tients during hospitalization.

(2) Establish a phone/video line between the patients and their family

We provided a mobile phone for COVID-19 wards to establish a video/phone call between patients and their family, if requested.

(3) Pay attention to walk-out time

If a hospital ward has a separated exit, short term walkout can be of help.

\section{(4) Use more verbal communication}

Due to restricted non-verbal communication, more verbal communication is recommended.

(5) Address the anxiety and depression with direct questions

Physicians should regularly ask questions about symptoms of anxiety, depression, and insomnia along with other COVID-19 symptoms (4).

(6) Provide professional care for psychological distress

Low doses of antianxiety medications, such as lorazepam (5) and gabapentin, which do not interfere with cur-

$\uparrow$ What is "already known" in this topic:

Patients with COVID-19 may experience psychological problems during hospitalizations.

$\rightarrow$ What this article adds:

Using simple and small adjustments in addressing psychological distress in COVID-19 patients may help their mental health during hospitalization. 
rent medications, may be prescribed for COVID-19 patients. Online psychological interventions such as relaxation techniques can also help COVID-19 patients to deal with their anxiety (6).

\section{(7) Do not forget to inform families}

In our hospital, to minimize the risk of transmission, medical students were exempted from going to COVID-19 wards. Instead, they were asked to operate telephone follow-up service to provide information on the patient's medical situation. In addition to helping families, it was a valuable educational experience for the trainees. Families reported this service reduced their worries and they were more prepared for hearing bad news.

\section{(8) Address families' concerns}

In our hospital, some of the families were in denial. Several studies provided evidence for the effectiveness of telehealth, especially in the context of depression (7), anxiety(8) and PTSD (9). Therefore, online psychological counseling with the patients' family members could help them cope with stress and its psychological consequences.

\section{Mental health care in the Intensive care unit (ICU)}

\section{(1) Empathic communication could prevent PTSD}

Empathy, reassurance, and listening to the concerns of the COVID-19 patients encountering a life-threatening condition can play a protective role against PTSD (10).

(2) Address the patient anxiety or depression with direct questions

Physicians should ask about anxiety and depression in patients, as they can worsen the underlying breathing problem and their management may prevent PTSD.

(3) Provide professional care for psychological distresses

The use of help line or video call for psychological interventions in patients with COVID-19 (such as relaxation technique) can reduce the risk of PTSD, particularly if started in ICU (11). If patients are unable to speak, the written call can be used.

If not effective, pharmacological treatments can also be offered based on the etiology of anxiety. Consider antianxiety medication in a low dose with limited duration.

\section{(4) Implement preventive measure for delirium}

Implementing preventive measures for delirium, such as early ambulation, a daily reminder of time and place, talking to the family members or friends on a video call, regulation of sleep-wake cycle, respiratory physiotherapy, the regulation of water and electrolyte level, avoiding overuse of the sedative-hypnotics and neuromuscular blockers, should be taken into consideration $(12,13)$. The latter is especially important given the early anecdotal report of advantages of prone position in COVID-19 patients, which usually leads to requiring higher doses of sedatives (14).
(5) Palliative care should be in mind

All patients with COVID-19 who are on the verge of death should receive palliative care (for symptoms such as anxiety, pain, shortness of breath, and nausea); thus, requests for palliative care should be examined before the illness worsens (15)

\section{(6) Follow-up families of deceased}

We dealt with a lot of pathological grieves in survivors who did not have the chance of proper bereavement. Therefore, we arranged for a follow-up of bereaved families by trained medical students in our hospital. Let the family members say their last goodbyes to the dying patients using virtual contact $(15,16)$

\section{Conclusion}

Hospitalization services for COVID-19 patients may be initially poor-coordinated. A multidisciplinary team of experts alongside psychiatrists could tackle challenging mental health conditions to provide a coordinated care program. Using simple and small adjustments in addressing psychological distress in COVID-19 patients may help their mental health during hospitalization. Therapists can help their patients only if they themselves are in good physical and mental health conditions.

\section{Acknowledgment}

The authors wish to thank Rasoul Akram Hospital Clinical Research Development Center (RCRDC), Iran University of Medical Sciences for its editorial assistance.

\section{Conflict of Interests}

The authors declare that they have no competing interests.

\section{References
1. World Health Organization. Avaliable from: https://www.who.int/emergencies/diseases/novel-coronavirus- 2019/situation-reports.}

2. Yang L, Wu D, Hou Y, Wang X, Dai N, Wang G, et al. Analysis of psychological state and clinical psychological intervention model of patients with COVID-19. medRxiv. 2020.

3. Varatharaj A, Thomas N, Ellul MA, Davies NW, Pollak TA, Tenorio EL, et al. Neurological and neuropsychiatric complications of COVID19 in 153 patients: a UK-wide surveillance study. Lancet Psychiatry. 2020; S2215-0366(20)30287-X.

4. Browne D, Roy D, Philips D, Stephenson D, Shamon D. Supporting Patient and Clinician Mental Health during COVID-19 via TraumaInformed Interdisciplinary Systems. 2020. Avaliable from: https://deepblue.lib.umich.edu/handle/2027.42/154741.

5. Battaglia J. Pharmacological management of acute agitation. Drugs. 2005;65(9):1207-22.

6. Breen LJ, Aoun SM, O'Connor M, Howting D, Halkett GK. Family caregivers' preparations for death: a qualitative analysis. J Pain Symptom Manage. 2018;55(6):1473-9.

7. Haregu TN, Chimeddamba O, Islam MR. Effectiveness of telephonebased therapy in the management of depression: a systematic review and meta-analysis. SM J Depress Res Treat. 2015;1(2):1006.

8. Rees CS, Maclaine E. A systematic review of videoconference-delivered psychological treatment for anxiety disorders. Aust Psychol. 2015;50(4):259-64.

9. Turgoose D, Ashwick R, Murphy D. Systematic review of lessons learned from delivering tele-therapy to veterans with post-traumatic stress disorder. J Telemed Telecare. 2018;24(9):575-85.

10. Moss J, Roberts MB, Shea L, Jones CW, Kilgannon H, Edmondson 
DE, et al. Healthcare provider compassion is associated with lower PTSD symptoms among patients with life-threatening medical emergencies: a prospective cohort study. Intens Care Med. 2019;45(6):815-22.

11. Roberts MB, Glaspey LJ, Mazzarelli A, Jones CW, Kilgannon HJ, Trzeciak S, et al. Early interventions for the prevention of posttraumatic stress symptoms in survivors of critical illness: a qualitative systematic review. Cri Care Med. 2018;46(8):1328-33.

12. Trogrlić Z, van der Jagt M, Bakker J, Balas MC, Ely EW, van der Voort PH, et al. A systematic review of implementation strategies for assessment, prevention, and management of ICU delirium and their effect on clinical outcomes. Crit Care. 2015;19(1):157.

13. Brummel NE, Girard TD. Preventing delirium in the intensive care unit. Crit Care Clin. 2013;29(1):51-65.

14. Meng L, Qiu H, Wan L, Ai Y, Xue Z, Guo Q, et al. Intubation and Ventilation amid the COVID-19 OutbreakWuhan's Experience. Anesthesiology. 2020;132(6):1317-32.

15. Borasio GD, Gamondi C, Obrist M, Jox R. COVID-19: decision making and palliative care. Swiss Med Wkly. 2020;150(1314).

16. Otani H, Yoshida S, Morita T, Aoyama M, Kizawa Y, Shima Y, et al. Meaningful communication before death, but not present at the time of death itself, is associated with better outcomes on measures of depression and complicated grief among bereaved family members of cancer patients. J Pain Symptom Manage. 2017;54(3):273-9. 